\title{
AVALIAÇÃO DE FICHAS TÉCNICAS DE VESTUÁRIO QUANTO AO CONTEÚDO INFORMACIONAL
}

\section{EVALUATION OF TECHNICAL PACK DATA REGARDING INFORMATIONAL CONTENT}

\author{
Ana Laís de Oliveira Monte ${ }^{1}$, M.Sc. \\ Raimundo Lopes Diniz², D.Sc. \\ (1) Universidade Federal do Maranhão- UFMA \\ e-mail: analais_monte@hotmail.com \\ (2) Universidade Federal do Maranhão- UFMA \\ e-mail:rl.diniz@ufma.br
}

Palavras-chave: fichas técnicas de vestuário, conteúdo informacional, ergonomia informacional

Esta pesquisa tem como objetivo avaliação do conteúdo informacional das fichas técnicas de vestuário da cidade de São Luís-MA através do protocolo de Mijksenaar. Como resultados, percebeu-se que as fichas não possuem padrão, quanto a sua apresentação gráfica e informacional e não seguem parâmetros de boa legibilidade e leiturabilidade.

Key-words: technical pack data, informational content, informational ergonomics

This study is about an evaluation of the informational content related to technical pack data in São Luís city, Maranhão state, through the protocol of Mijksenaar. Findings appointed that the tech pack data have no pattern in terms of their graphical and informational presentation and they do not follow parameters of good legibility and readability.

\section{Introdução}

O vestuário é uma das categorias mais privilegiados pelo sistema da moda e observa que para sua produção, necessita-se de um conjunto de artefatos que são articulados por meio de metodologias e processos criativos desenvolvidos por designers na indústria (MESQUITA, 2004).

Para desenvolver produtos de vestuário de moda é preciso entender todo o processo produtivo, com um planejamento definido e uma boa estrutura organizacional, já que as indústrias de confecção transformam tecido em peça do vestuário com o objetivo de projetar desejo e necessidade nos 


\section{$16^{\circ}$ \\ ERGODESIGN USIHC CINAHPA}

consumidores finais.

$\mathrm{O}$ desenvolvimento de produto de moda no vestuário envolve diversas atividades com etapas sucessivas para transformação do mesmo. Estão relacionadas ao desenvolvimento do produto etapas de planejamento da coleção, pesquisa de tendência de moda, pesquisa de materiais, criação do modelo, modelagem, peça-piloto, ficha técnica, Planejamento e Controle da Produção (PCP), corte, confecção, acabamento e expedição

Rosa (2007), enfatiza que a ficha técnica é um documento no qual se catalogam todas as informações essenciais para construção do produto de vestuário.

A ficha técnica do vestuário é um instrumento que passa por todo o processo produtivo, desde a criação, modelagem, prototipagem, corte e acabamento das peças. Logo, ela precisa ser compreendida por toda produção para evitar erros e viabilizar o PCP (Planejamento e Controle da Produção).

Para isso, o design da informação e a ergonomia informacional são cruciais na elaboração das fichas técnicas, pois servirá de instrumento para transmitir a mensagem de maneira eficaz entre o emissor e o receptor e, assim, facilitar a compreensão dos possíveis ruídos. Segundo Moraes (2002), a recepção da mensagem surge como um processo que é compreendido por quatro fenômenos distintos: a atenção, a percepção, compreensão e a memorização.

O Citeve (2005) ainda relata os efeitos positivos resultantes da utilização das fichas técnicas, que são estes:

- $\quad$ Correta definição de produtos e processos;

- $\quad$ Maior previsão das necessidades, tempos e custos;

- $\quad$ Comunicação formal, rápida e eficiente;

- $\quad$ Produzir bem à primeira vez;

- $\quad$ Eliminação/redução de enganos e mal- $16^{\circ}$ Ergodesign - Congresso Internacional de Ergonomia e Usabilidade de Interfaces Humano Tecnológica: Produto, Informações Ambientes Construídos e Transporte

$16^{\circ}$ USIHC - Congresso Internacional de Ergonomia e Usabilidade de Interfaces Humano Computador

CINAHPA | 2017 - Congresso Internacional de Ambientes Hipermídia para Aprendizagem.

entendidos;

- $\quad$ Eliminação/ redução de tempo improdutivo;

- $\quad$ Ciclo produtivo mais rápido;

- $\quad$ Aumento da produtividade global da empresa;

- $\quad$ Criação de uma imagem de confiança e qualidade.

Tendo em vista a relevância do estudo da ficha técnica, é importante salientar que elas são usadas por pessoas em indústrias do vestuário. Estas, precisam se capacitar, bem como estudantes e pesquisadores, precisam inclusive de um fundamento cientifico teórico acerca da ficha técnica, pois a bibliografia acerca do tema ficha técnica do vestuário ainda é pouco explorada, pouco lembrada nos livros de desenho técnico, já que há poucas pesquisas desenvolvidas sobre o tema, havendo uma necessidade de maiores esclarecimentos sobre essa temática.

Assim as fichas foram escaneadas em resolução máxima, mantendo a integralidade das mesmas de maneira a analisar também os itens escritos manualmente, bem como a razão figura fundo na impressão, conservando a significância das informações relevantes.

Dessa forma, o presente artigo busca a avaliação de fichas técnicas quanto ao seu conteúdo informacional. O objetivo é reconhecer tecnicamente se as fichas técnicas em questão foram elaboradas para que o seu usuário consiga otimizar suas tarefas relativas à execução do desenvolvimento de vestuários.

\section{Ergonomia informacional para o design de fichas técnicas}

A ergonomia informacional utiliza os princípios da teoria da informação de maneira a "enviar a informação correta para a pessoa certa no momento exato, de forma eficaz e eficiente. Dessa maneira, satisfaz o usuário respeitando sempre a 
sua diversidade em termos de habilidades e limitações." (CAVALCANTI, 2009, p 3).

Nessa tessitura a ficha técnica do produto deve conter todas as informações pertinentes ao desenvolvimento de produto, incluindo custos, além de incorporar informações fundamentais para o planejamento de compras e matéria-prima, complementa Ringueiral (2002).

A ênfase dada por Moraes e Mont'Alvão (2007) é bem oportuna quando fala da importância dos enfoques sistêmicos informacionais. A ergonomia como organização do trabalho e operacionalização da tarefa tem os seguintes parâmetros informacionais: "a visibilidade, legibilidade, compreensibilidade e quantidade de informações, priorização e ordenação, padronização, compatibilização e consistência, componentes sígnicos: caracteres alfanuméricos e símbolos iconográficos" (p.14). Esses parâmetros podem servir como instrumentos para analisar as fichas técnicas.

Alguns ruídos ergonômicos podem comprometer o entendimento da ficha técnica. Moraes (2002) complementa que podem afetar a comunicação, principalmente no que diz respeito à ergonomia informacional:

- As fontes tipográficas no nível de visibilidade, legibilidade e leiturabilidade;

- Informações pictográficas com decodificação e compreensibilidade, dificulta a cognição e a tomada de decisão pelo usuário;

- Iluminação a deficiência ou excesso;

- Topologia dos componentes informacionais como mostradores, telas, painéis;

- A desconsideração de modelos mentais já existentes, acarreta sobrecarga cognitiva.

Frascara (2011) completa que a informação deve ser acessível, de maneira fácil, apropriada ao conteúdo do usuário, atrativa e convidativa a ser compreendida, confiável, concisa, completa, relevante de acordo com o interesse do usuário, $16^{\circ}$ Ergodesign - Congresso Internacional de Ergonomia e Usabilidade de Interfaces Humano Tecnológica: Produto, Informações Ambientes Construídos e Transporte

$16^{\circ}$ USIHC - Congresso Internacional de Ergonomia e Usabilidade de Interfaces Humano Computador

CINAHPA | 2017 - Congresso Internacional de Ambientes Hipermídia para Aprendizagem.

oportuna estando onde e quando o usuário necessita dessa informação. Moraes (2002) corrobora ao afirmar que:

"O homem recebe os sinais, decodifica os signos e age. A partir dos seus sistemas sensórioperceptivos detecta, discrimina e interpreta informações; através de processos cognitivos seleciona, trata informações, define estratégias e toma decisões - atividades não aparentes; envia mensagens através dos sistemas efetores e atua sobre os comandos de máquinas e equipamentos, movimenta o corpo e assume posturas, conforme exigências de visualização, manipulação e audição, desloca-se no espaço - atividades aparentes e observáveis" Moraes (2002. p.26).

Assim, a ficha deve conter informações preexistentes que minimizem o esforço do usuário e que fixe a atenção na informação por meio da cognição. Leite e Veloso (2014) corroboram que esse documento tem como objetivo informar dados peculiares do produto a ser produzido pela indústria.

\section{Métodos e técnicas}

Para análise das fichas técnicas e suas características informacionais serão consideradas as variáveis de Mijksenaar (2001).

Dentre as variáveis gráficas de Mijksenaar, serão analisadas três subvariáveis:

1) Diferenciadoras: que analisa a cor de fundo, quanto às variações possíveis existentes, as fontes tipográficas identificando a existência ou não de serifa, para palavras isoladas sem serifas serão mais legíveis (Prince, 1976), bem como tamanho da fonte e o uso de maiúsculo e minúsculo dando hierarquia aos itens da ficha técnica.

2) Hierárquicas: que consideram a importância dada a uma determinada informação. A posição da página (layout) será levada em consideração, se ela estiver em modo paisagem ou retrato. A sequência cronológica será outro ponto importante, já que será verificada a existência da sequência cronológica e logica, ou a necessidade de um 


\section{$16^{\circ}$ \\ ERGODESIGN USIHC CINAHPA}

suporte numérico para auxiliar a sequência de produção da peça. O tamanho do tipo deve estar entre 8 e 14, pois tipos muito pequenos dificultam a legibilidade conforme o quadro 01 . Os tamanhos também podem ser usados para hierarquizar os elementos gráficos, bem como devem estar em caixa baixa, ter tipo regular (ou redonda). A entrelinha deve ter tamanho igual ou maior que o corpo tipográfico para facilitar a leitura.

3) Suporte: subvariável que dará ênfase e estará relacionada aos atributos do texto, como linhas, boxes, colunas e existência dos símbolos. Os logotipos e o uso de negrito e itálico são usados para dar ênfase na informação.

A análises das fichas técnicas foram estruturados de acordo com o protocolo apresentado no Quadro 1 , a seguir.

\begin{tabular}{|l|l|l|l|}
\hline \multicolumn{2}{|l|}{} & \multicolumn{2}{l|}{ Local de coleta da ficha técnica } \\
\hline $\begin{array}{l}\text { Tipo de ficha técnica } \\
\text { fundo }\end{array}$ & $\begin{array}{l}\text { Fonte } \\
\text { tipográfica }\end{array}$ & $\begin{array}{l}\text { Ilustração/ } \\
\text { Desenho } \\
\text { técnico }\end{array}$ & \\
\hline $\begin{array}{l}\text { Posição da } \\
\text { página }\end{array}$ & $\begin{array}{l}\text { Sequência } \\
\text { cronológica }\end{array}$ & $\begin{array}{l}\text { Tamanho e } \\
\text { peso da } \\
\text { tipografia }\end{array}$ & \\
\hline Área de cor & $\begin{array}{l}\text { Linhas, } \\
\text { colunas ou box }\end{array}$ & $\begin{array}{l}\text { Símbolos, } \\
\text { logotipos }\end{array}$ & Negrito, \\
itálico
\end{tabular}

Quadro 1 - Exemplo de protocolo utilizado na análise das fichas técnicas

Fonte: Autora, (2017) $16^{\circ}$ Ergodesign - Congresso Internacional de Ergonomia e Usabilidade de Interfaces Humano Tecnológica: Produto, Informações Ambientes Construídos e Transporte

$16^{\circ}$ USIHC - Congresso Internacional de Ergonomia e Usabilidade de Interfaces Humano Computador

CINAHPA | 2017 - Congresso Internacional de Ambientes Hipermídia para Aprendizagem.
Dessa maneira, será possível organizar e avaliarr a estrutura e os elementos gráficos das fichas técnicas de vestuário.

A discussão das avaliações das fichas técnicas é baseada nas informações gráficas contidas nas fichas e analisadas a partir do protocolo desenvolvido pela pesquisadora através das variáveis de Mijkenaar (2001).

Estes resultados são apresentados separadamente quanto aos cinco modelos de fichas técnicas encontradas nas fábricas de São Luís-MA. Os modelos encontrados foram 3 (três) fichas técnicas de pedido, 1 (uma) ficha técnica de corte, 1 (uma) ficha técnica de confecção.

\section{Resultados e discussões}

\subsection{Avaliação do conteúdo informacional das fichas técnicas}

\section{A) Empresa A}

A figura 1 apresenta a ficha técnica de vestuário cedida pela empresa A.
Realização:

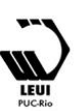


$16^{\circ}$ USIHC - Congresso Internacional de Ergonomia e Usabilidade de Interfaces Humano Computador

CINAHPA | 2017 - Congresso Internacional de Ambientes Hipermídia para Aprendizagem.
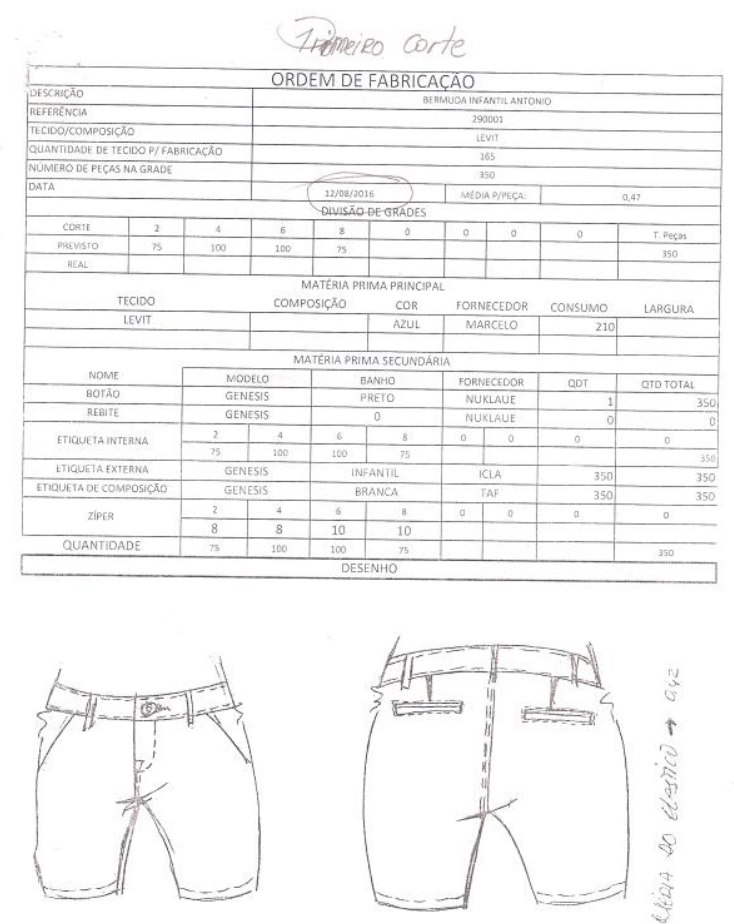

Figura 1 - Ficha técnica de corte na empresa A.

A ficha técnica da empresa A, também chamada ordem de serviço pela empresa, é classificada como ficha técnica de corte, segundo Araújo (1999), pois segue para o setor de corte para orientações de corte. Ela está dividida em 2 (duas) páginas e encontra-se na posição retrato. Não possui cabeçalho da empresa conforme Leite e Veloso (2014) orientam.

A ficha possui única fonte tipográfica de modelo simples, que de acordo com IIda (2016) facilita a leitura. Possui tamanho variando entre 8 e 10 , ideal para uma boa leiturabilidade de acordo com Warde (1999), no entanto parar o título apresenta fonte tipográfica 16. Ela possui apenas um tipo de fonte tipográfica, pois conforme Sousa (2002) uma grande variação tipográfica pode trazer ruídos. Possui palavras isoladas sem serifa que segundo Prince (1976) torna palavras isoladas mais legíveis. E ainda possui apenas letras maiúsculas que podem interferir no tempo de leitura e podem gerar desconforto (IIDA 2016, TINKER 1963).

O kerning são espaços vazios que aparecem em torno da letra, pois se as letras de uma fonte forem espacejadas de modo muito uniforme, produzirão um padrão pouco uniforme (LUPTON, 2006). sem necessidade da utilização do kerning (LUPTON, 2006). A ficha não possui variante tipográficos como negrito e itálico, segundo Mclean (1980), eles dariam ênfase à informação.

Possui fundo branco e fonte preta, sem nenhuma outra cor, que geram a oposição fundamental para a compreensão (HAMMERDCHMIDT, 2014). Possui sequência cronológica intuitiva, sem reforço numérico para orientar a ordem de análise.

Com desenho técnico do vestuário manual pouco preciso que contêm poucos detalhes da costura faltando conter mais informações que conforme Lodi (2013), relata que o desenho não pode deixar dúvidas para a produção. Não contem logotipo ou símbolo da empresa. A ficha possui uma sequência cronológica intuitiva das etapas sem ser necessário suporte para a orientação da sequência.

A ficha é composta por linhas e colunas, que auxiliam na hierarquização conforme parâmetros de Lupton (2006). O alinhamento da ficha inicialmente é para a esquerda, pois facilita a compreensão, e logo em seguida se centralizam. A utilização de negrito é inexistente e a sua falta não interfere na legibilidade (MCLEAN, 1980).

\section{B) Análise do conteúdo informacional da ficha técnica de confecção na empresa $A$}

A figura 2 e 3 apresentam a ficha técnica de vestuário cedida pela empresa $\mathrm{A}$.
Realização:
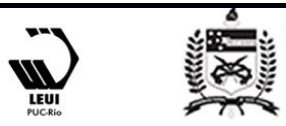
$16^{\circ}$ USIHC - Congresso Internacional de Ergonomia e Usabilidade de Interfaces Humano Computador

Figura 2 - Ficha técnica de confecção na empresa A.

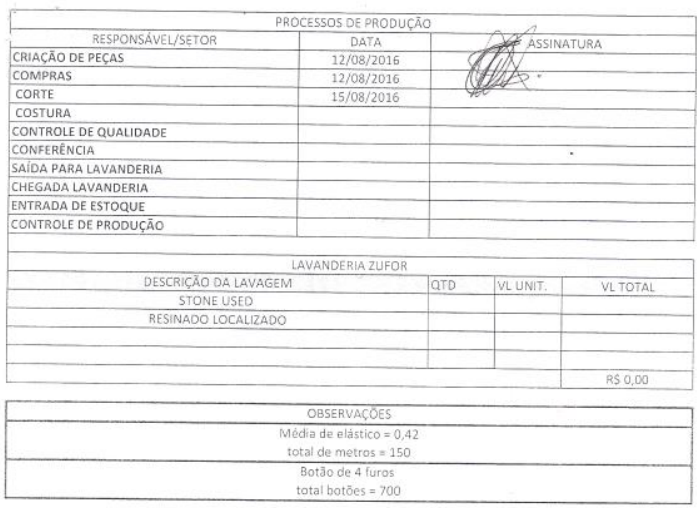

Figura 3 - Ficha técnica de confecção na empresa A.
A ficha técnica foi classificada como de ficha de confecção, que é, conforme Araújo (1999), uma ficha provisória, já que pode ocorrer alterações, onde pode conter a sequência operacional e o tempo das operações. No entanto, essa ficha não apresenta esses dados. Ela se mostra pouco legível com informações soltas, já que é preenchida manualmente, o que pode dificultar a compreensão das letras cursivas.

A presente ficha possui fundo branco, com letras pretas pouco legíveis, possui uma única fonte tipográfica que Sousa (2002) melhora a leitura, pois diversos tipos de fontes podem apresentar dificuldades de compreensão. No entanto apresentam tamanhos tipográficos entre 10 e 12 para o texto facilitando a leiturabilidade e legibilidade e para títulos uma fonte 10 e letras maiúsculas, neste critério seguindo as recomendações de IIda (2006).

Possui um pequeno espaço para desenho técnico que pode atrapalhar nos seus detalhes, pois segundo Lodi (2013) deve existir detalhamento do desenho técnico. O termo "desenho técnico" encontra-se em fonte reduzida com serifa e em negrito que atrapalha a leiturabilidade conforme Morris et. al. (2001, apud Poole, 2005). Nesta ficha não aparece nenhuma outra cor.

A posição da ficha encontra-se em modo retrato, já a sequência cronológica é intuitiva e não precisa de auxilio numérico. Os diferentes tamanhos de fonte tipográfica e o uso de caixa alta nos títulos trazem conforto na leitura, pois segundo Iida (2016), elas auxiliam a hierarquização da ficha.

A utilização de diagramas com linha e colunas auxilia o processo de hierarquização da ficha técnica. Lupton (2006) relata que funcionam muito bem e ainda que podem criar zonas especificas para cada conteúdo. Nenhum símbolo ou logotipo foi encontrado.

\section{C) Análise do conteúdo informacional da ficha técnica de pedido na empresa $B$}

A figura 4 apresenta a ficha técnica de
Realização:

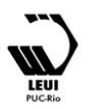


$16^{\circ}$ Ergodesign - Congresso Internacional de Ergonomia e Usabilidade de Interfaces Humano Tecnológica: Produto, Informações Ambientes Construídos e Transporte

$16^{\circ}$ USIHC - Congresso Internacional de Ergonomia e Usabilidade de Interfaces Humano Computador

CINAHPA | 2017 - Congresso Internacional de Ambientes Hipermídia para Aprendizagem. vestuário cedida pela empresa $B$.

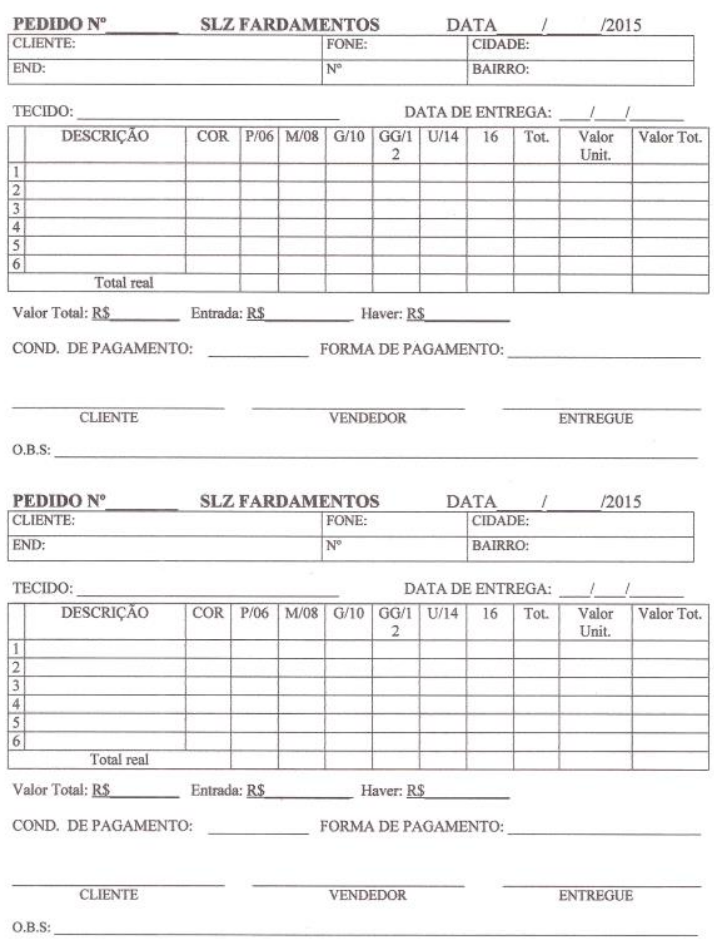

Figura 4 - Ficha técnica de pedido na empresa B.

A ficha técnica de pedido da empresa B, é classificada de acordo com Araújo (1999). Ela é utilizada pelo departamento comercial para realizar o pedido e é uma ficha simples, que possui cabeçalho conforme orientação de Leite e Veloso (2014). Possui apenas o nome da empresa, com fundo branco, com fonte preta gerando contraste. A ficha conforme orientação de Hammerschmidt (2014), o tipo possui dois tamanhos: 12 e 14, que segundo Waaede (1999) é a diretriz ideal para leitura.

No decorrer de toda ficha técnica utiliza-se a mesma fonte tipográfica que é recomendada por Sousa (2002). Também se utiliza de palavras isoladas com serifa, em conformidade com as diretrizes de Prince (1976). Deve-se utilizar letras maiúsculas para títulos dentro dos boxes, pois conforme os parâmetros de IIda (2016), elas podem auxiliar na leitura. A pouca utilização de letras minúsculas para subtítulos compromete a compressão.

Ela não possui desenho técnico, pois a empresa trabalha apenas com produção de blusas de malhas e fardamento, fazendo uso da peça piloto como reprodução. Existe apenas um pequeno box para descrever o modelo, a grade de tamanho, os valores, bem como pagamentos, vendedor e informações sobre o cliente.

A posição do layout da ficha é retrato, na qual está a duplicada, para que possa ser recortada e ficar uma via para o cliente no entanto, deveria ter mais informações da empresa no cabeçalho, caso o cliente precise. Quanto à sequência lógica, não necessita de suporte numérico para compreendê-la.

Existe a utilização de linhas e colunas hierarquizando os itens, juntamente com as diferenças de tamanhos dos tipos e a utilização de negrito. Para isso, ela possui variações de cores em toda a ficha.

\section{D) Análise do conteúdo informacional da ficha técnica de pedido na empresa $\mathrm{C}$}

A figura 5 apresenta a ficha técnica de vestuário cedida pela empresa C. 


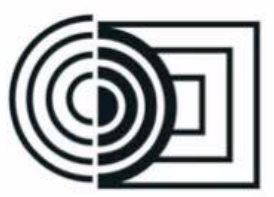

$16^{\circ}$ Ergodesign - Congresso Internacional de Ergonomia e Usabilidade de Interfaces Humano Tecnológica: Produto, Informações Ambientes Construídos e Transporte

$16^{\circ}$ USIHC - Congresso Internacional de Ergonomia e Usabilidade de Interfaces Humano Computador

CINAHPA | 2017 - Congresso Internacional de Ambientes Hipermídia para Aprendizagem.

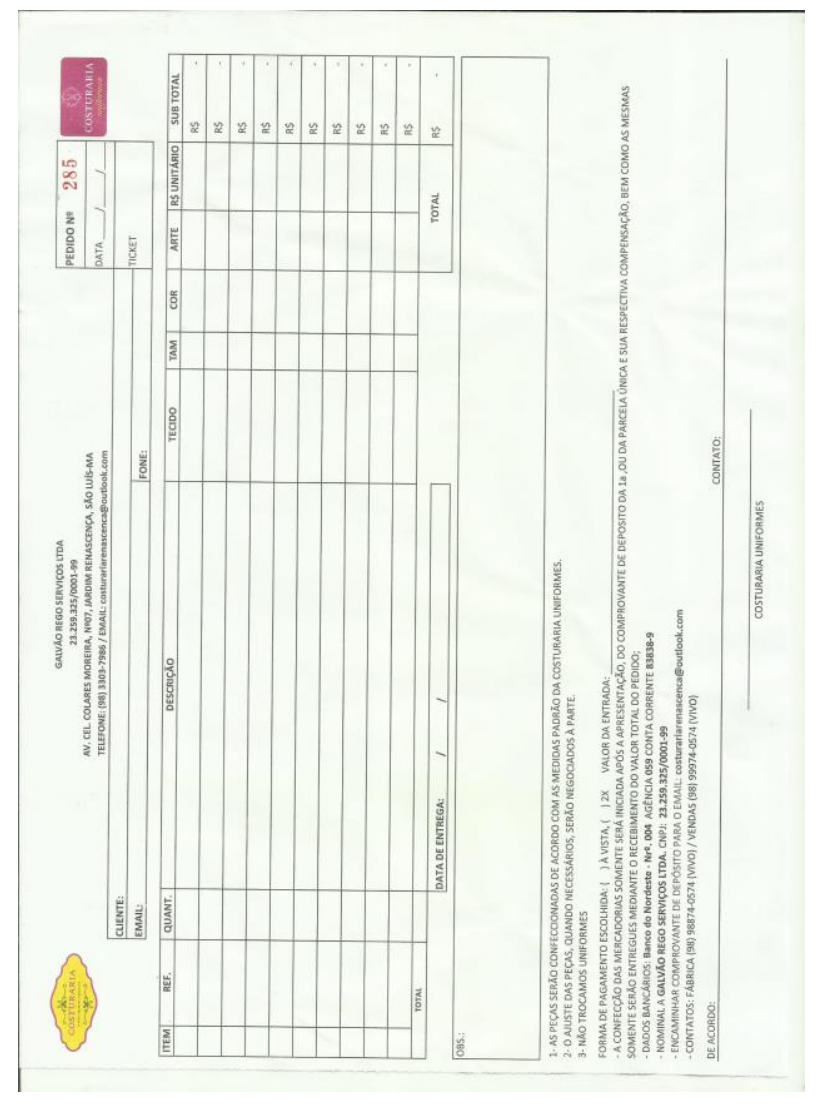

Figura 5 - Ficha técnica de pedido na empresa C.

A ficha técnica de pedido da empresa Cé classificada de acordo com Araújo (1999). Ela é utilizada pelo departamento comercial para realizar o pedido e é uma ficha mais completa que da empresa $\mathrm{B}$, pois possui um cabeçalho completo com todas as informações sobre a empresa. Ela é emitida em duas vias, uma, e possui logotipo da empresa, fica para o cliente.

A ficha é bem clara com espaços para referência, quantidade e descrição, já que as peças são confeccionadas a partir da peça de mostruário, não sendo necessário usar o desenho técnico, pois a empresa produz apenas fardamentos seguindo seu mostruário. O que pode variar da peça de mostruário é o tecido, cor e arte (bordado). Todas essas informações possuem na ficha técnica de pedido.

Possui também previsão de entrega e espaço para colocar observações, caso necessário. Contém ainda detalhamento das informações de produção, bem como a forma de pagamento e entrega detalhada, evitando assim dúvidas posteriores.

A ficha possui dois tamanhos tipográfico 8 e 9 , que conforme Waarde (1999) está dentro do padrão para boa leitura e é empregado um tipo mais simples. Para Iida (2016), os tipos rebuscados podem dificultar a leitura. A fonte tipográfica não possui serifa, pois segundo Morris, et. al. (2001 apud Poole 2005) o tamanho reduzido da serifa pode gerar ruídos.

A ficha está predominantemente em letra maiúscula, que de acordo com Tinker (1963), foge dos parâmetros de boa leiturabilidade. Mas, segundo Iida (2016), quando utilizada em títulos pode auxiliar compreensão, conforme modelo da ficha.

A ficha possui negrito nos títulos, dando ênfase e auxiliando a hierarquização da ficha técnica, pois, conforme os critérios de Mclean (1980), auxiliam a compreensão dos elementos. O espaçamento entre as letras é regular, não gera conflitos tipográficos e não compromete a leitura que, segundo Hammerschidt (2014), é ideal para legibilidade.

A ficha possui layout no modo paisagem, com cores apenas nos logotipos e em vermelho o número do pedido. O documento ainda apresenta uma sequência cronológica intuitiva. Já as linhas e colunas facilitam a hierarquização dos itens, de tal modo a concordar com Lupton (2006) quando relata que cria zonas especificas para cada conteúdo.

\section{E) Análise do conteúdo informacional da ficha técnica de pedido 2 na empresa $C$}

As figuras 6, 7 e 8 apresentam mais um modelo de ficha técnica de vestuário cedida pela empresa C. 


\section{$16^{\circ}$ \\ ERGODESIGN USIHC CINAHPA}

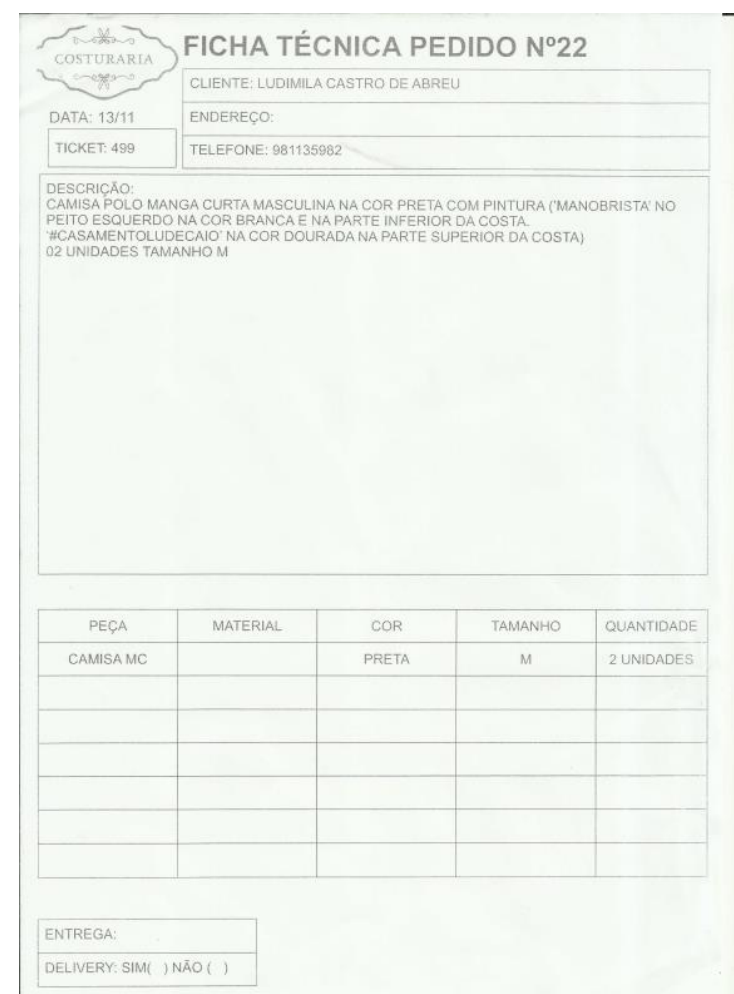

Figura 6 - Ficha técnica de pedido 2 na empresa $C$, pag. 1

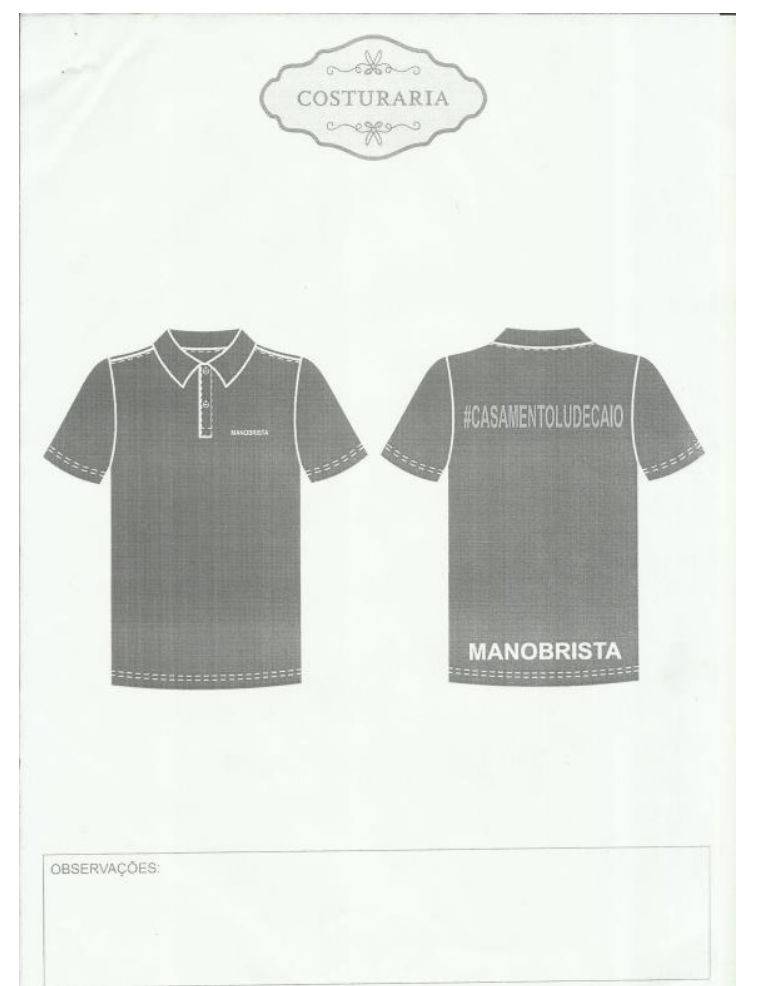

figura 7-Ficha técnica de pedido 2 na empresa C, pág. 2 $16^{\circ}$ Ergodesign - Congresso Internacional de Ergonomia e Usabilidade de Interfaces Humano Tecnológica: Produto, Informações Ambientes Construídos e Transporte

$16^{\circ}$ USIHC - Congresso Internacional de Ergonomia e Usabilidade de Interfaces Humano Computador

CINAHPA | 2017 - Congresso Internacional de Ambientes Hipermídia para Aprendizagem.
Figura 8 - Ficha técnica de pedido 2 na empresa C, pág. 3

A ficha técnica de pedido da empresa C, é classificada de acordo com Araújo (1999). Ela é utilizada pelo departamento comercial para realizar o pedido é uma ficha mais completa que o modelo 1 , no que se refere a informações da peça, possui informações do cliente, com a descrição da peça na primeira página e o desenho técnico na segunda página.

Esta é uma ficha que fica apenas na empresa e que se destina a tirar dúvidas da peça. Na página 3 possui espaço para lista de materiais e sequência de produção, que não são utilizadas, pois a peça é produzida em unidade, apenas uma costureira detém todas as etapas de produção.

A ficha possui tipo tamanho 12, que conforme as referências de Waarde (1999), é a ideal para boa leiturabilidade, mas para o título possui fonte tamanho 24. Não é necessário organizar o espaçamento entre as letras, nem entre as palavras. Os espaçamentos entre as letras das palavras se 


\section{$16^{\circ}$ \\ ERGODESIGN USIHC CINAHPA}

apresentam de maneira uniforme, sem necessidade da utilização do kerning (LUPTON, 2006). Assim, o tracking organiza o espaçamento entre as palavras aumentando ou diminuindo os espaços. (Sousa, 2002), não sendo necessário a utilização do kerning e o traking nas fichas. No entanto, apresenta-se toda com letra maiúscula que, de acordo com Tinker (1963), gera ruídos no tempo de leitura do texto.

Já as linhas, colunas e box setoriza os assuntos que em concordância com Lupton (2006), auxiliam a hierarquização das informações. Possui negrito apenas nos dois últimos títulos, que não são utilizados, e no cabeçalho. Possui o logotipo da empresa. A sequência cronológica é intuitiva.

\subsection{Recomendações especificas ao design das fichas técnicas}

As fichas técnicas em analises possuíam aspectos positivos e negativos, deste modo é oportuno salientar que para a melhoria das mesmas devem seguir orientações.

Como recomendações específicas para um bom design fichas técnicas, conforme resultados deste estudo, e em consonância com a literatura sobre $o$ tema, propõe-se o seguinte:

1. Ilustrações/desenhos técnicos devem ser mais precisos e completos, não podem faltar

informações a fim de sanar as dúvidas.

2. As informações adicionais devem ser transcritas para auxiliar o reconhecimento dos detalhes, bem como deve conter o máximo de detalhamento para produção da peça conforme orienta Rosa (2007), Ringueiral (2002) e Lidório (2008), Civete (2005).

3. Elementos textuais devem ter fonte maior que 8 e menor que 14 , pois tipos muito pequenos podem comprometer o entendimento, conforme Waare (1999)

4. Elementos de ênfase como, linhas, colunas, negrito e itálico devem ser utilizados para mostrar detalhes da tarefa, bem como hierarquizar elementos. $16^{\circ}$ Ergodesign - Congresso Internacional de Ergonomia e Usabilidade de Interfaces Humano Tecnológica: Produto, Informações Ambientes Construídos e Transporte

$16^{\circ}$ USIHC - Congresso Internacional de Ergonomia e Usabilidade de Interfaces Humano Computador

CINAHPA | 2017 - Congresso Internacional de Ambientes Hipermídia para Aprendizagem.

5. A ficha deve seguir uma ordem cronológica, de maneira que facilite a orientação das mesmas.

6. Ter acesso em qualquer lugar da empresa de forma fácil e intuitiva conforme orienta o manual do Citeve (2005).

\section{Considerações finais}

Desta maneira os objetivos da pesquisa foram alcançados. A partir das analises das fichas técnicas do vestuário quanto ao conteúdo informacional, foram encontrados cinco tipos de fichas técnicas, as quais foram analisadas a partir de um protocolo baseado nas variáveis de Mijksenaar (2001). Alguns parâmetros não foram utilizados no design das mesmas, apenas o tamanho da fonte em todas possuía tamanho maior que 8 .

Foi possível identificar na análise que as fichas não possuem padrão na forma da apresentação gráfica e do conteúdo informacional, e que não possuía uma boa hierarquização, o espaço para o desenho é insuficiente ou não possui descrição dos detalhes e as informações ainda são insuficientes para os usuários.

Assim é contribuição desta pesquisa é a sugestão para que as fábricas usem as informações de maneira hierarquizada, legível e de fácil leiturabilidade, para que os usuários das mais diversas fábricas compreendam os modelos diferentes de fichas técnicas utilizadas.

\section{Referências Bibliográficas}

ARAÚJO, M. Tecnologia do Vestuário. Lisboa: Fundação Calouste Gulbenkian, 1996.

\section{CAVALCANTI, J. F. Análise ergonômica da sinalização de segurança: um enfoque da ergonomia informacional e cultural. Dissertação em engenharia de produção UFPE. 2003.}

CITEVE. O manual do formador. Modulo 2: Planejamento e Organização da produção - Nível Básico. 2005. Centro tecnológico das indústrias 


\section{$16^{\circ}$ \\ ERGODESIGN USIHC CINAHPA}

$16^{\circ}$ Ergodesign - Congresso Internacional de Ergonomia e Usabilidade de Interfaces Humano Tecnológica: Produto, Informações Ambientes Construídos e Transporte

$16^{\circ}$ USIHC - Congresso Internacional de Ergonomia e Usabilidade de Interfaces Humano Computador

CINAHPA | 2017 - Congresso Internacional de Ambientes Hipermídia para Aprendizagem. têxtil e do vestuário de Portugal. Disponível em: http://elearning.iefp.pt/pluginfile.php/49825/mod_r esource/content/0/25617_ManualFormandoNivBas icoPlanOrgProdModulo2.pdf. Acesso em: 06 jul. 2016.

FRASCARA, J. Que és el diseño de comunicación? Buenos Aires: Ediciones Infinito, 2011.

HAMMERSCHMIDT, C. Tipografia em bulas de medicamentos digitais para acesso ao bulário eletrônico em dispositivos de interação móvel. Dissertação, Universidade federal do Paraná, 2014.

Iida, Itiro. Buarque, L. Ergonomia: projeto e produção. 3. ed. - São Paulo: Blucher, 2016.

LEITE, A. S.; VELLOSO, M. D. Desenho técnico da roupa feminina. 3. ed 5. reimpressão. Rio de Janeiro: Editora Senac Nacional, 2014.

LODI, R.; CATTANI, A. O papel do desenho técnico de moda do vestuário e nas escolas de moda. 8 COLOQUIO DE MODA. 2013.

LUPTON, E. Pensar como tipos: guia para designers, escritores, editores e estudantes. Tradução Andre Stolarski. São Paulo: CoscaNaify, 2006.

MCLEAN, R. The Thames and Hudson manual of Typography. Londres Thames \&Hudson, 1980.

MESQUITA, C. Moda Contemporânea. São Paulo, Editora Anhembi, 2004.

MIJKSENAAR, P. Una introduccíon al: deseño del información. Barcelona,. Editora Gustavo Gili, 2001

MORAES, A. Avisos, Advertências e Projetos de Sinalização: Ergodesign Informacional. Rio de Janeiro, 2002.

MORAES, A. MONT'ALVÃO, C. Ergonomia: conceitos e aplicações. Rio de Janeiro, 2007.

POOLE, A. Literature Review: Which Are More Legible: Serif or Sans Serif Typefaces? In: Alex
Poole - interaction design and research. Disponível em:

http://www.alexpoole.info/academic/literaturerevie w.html. Acesso em: 19/09/2016.

PRINCE, J. H. Printing for the visually handicapped. In: The Journal of Typographic Research, v.1, 1967.

RIGUEIRAL, C. Design \& Moda: como agregar valor e diferenciar sua confecção. São Paulo: instituto de pesquisa e tecnologia, Brasília, DF: ministério do desenvolvimento, indústria e comercio exterior, 2002.

ROSA, L. da. Ficha Técnica do Produto Aplicado ao Processo Produtivo do Vestuário. 2007. Anais do $3^{\circ}$ Colóquio de Moda.

SOUSA, M. Guia de tipos: método para uso de fontes de PC. 2002. Endereço eletrônico disponível em:

http://www.infoamerica.org/museo/pdf/guia_de_tip os01.pdf

TINKER, M, A. Legibility of print. Cambridge: University Press, 1963.

WAARDE, k. Typographic dimensions and conventional wisdom: a discrep- ancy? Technical Communication, v. 46, n. 1, 1999.

\section{Agradecimentos}

Os autores gostariam de agradecer às instituições FAPEMA e CAPES pelo apoio financeiro e incentivo à pesquisa. Agradeço também ao amigo Rubenio pelo apoio no desenvolvimento deste artigo.
Realização:

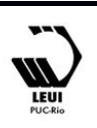

